\title{
Biossegurança e acidentes com material biológico na odontologia: considerações atuais
}

\author{
Biosafety and accidents with biological material in dentistry: current considerations \\ Bioseguridad y accidentes con material biológico en odontología: consideraciones \\ actuales
}

Kátia Ferreira dos Santos ${ }^{1 \star}$, Nilton José Fernandes Cavalcante².

\begin{abstract}
RESUMO
Objetivo: Identificar percepções dos cirurgiões-dentistas $(C D)$ sobre as causas de exposição à material biológico, caracterizar mudanças comportamentais e práticas biosseguras adotadas pelos profissionais, após os acidentes. Métodos: Estudo transversal qualitativo, retroprospectivo realizado em hospital público, São Paulo, Brasil. Foram realizadas entrevistas, com dois questionários semiabertos e aplicados em dois grupos de $20 \mathrm{CD}$ cada, no período de 2008 a 2012, selecionados, da notificação de 103 acidentes, pela Comissão de Controle de Infecção Hospitalar (CCIH). Estudo aprovado pelo Comitê de Ética em Pesquisa (CEP). Resultados: O momento do acidente e as mudanças decorridas permitiram a categorização do estudo, respectivamente: Ordem Pessoal, Ordem Técnica, Ordem de Trabalho, Reincidência de Acidente e Prevenção de Acidentes. Em ambos, a categoria Ordem Pessoal relatou fatores predisponentes para a ocorrência dos acidentes como desatenção, distração, estresse e fadiga. Já, mudanças ocorridas após o acidente relacionaram-se com: aumento no autocuidado, na atenção e biossegurança. Conclusão: As mudanças comportamentais relacionaram-se às práticas biosseguras, adesẩo aos equipamentos de proteção individual (EPI), aperfeiçoamento odontológico, autocuidado na atenção, nos limites pessoais e profissionais. As mudanças revelaram boas práticas de trabalho, adesão à imunização vacinal completa e sugestão a protocolos de atendimento, como coadjuvantes na segurança do trabalho.
\end{abstract}

Palavras-chave: Contenção de riscos biológicos, Acidentes de trabalho, Prevenção de acidentes.

\section{ABSTRACT}

Objective: To identify the perceptions of dentists (CD) about the causes of exposure to biological material, to characterize behavioural changes and biosafety practices adopted by professionals, after accidents. Methods: Qualitative cross-sectional, retrospective study carried out in a public hospital, São Paulo, Brazil. Interviews were carried out, with two semi-open questionnaires and applied in two groups of 20 DC each, from 2008 to 2012 , selected, from the notification of 103 accidents, by the Hospital Infection Control Commission (CCIH). Study approved by the Research Ethics Committee (CEP). Results: The moment of the accident and the changes that took place allowed the categorization of the study, respectively: Personal Order, Technical Order, Work Order, Accident Recurrence and Accident Prevention. In both, the Personal Order category reported predisposing factors for the occurrence of accidents such as inattention, distraction, stress, and fatigue. The changes that occurred after the accident were related to increased self-care, attention, and biosafety. Conclusion: Behavioural changes were related to biosafety practices, adherence to personal protective equipment (PPE), dental improvement, self-care in attention, within personal and professional limits. The changes revealed good work practices, adherence to full vaccination immunization and suggestion for care protocols, as supporting work safety.

Keywords: Containment of biohazards, Accidents occupational, Accident prevention.

\section{RESUMEN}

Objetivo: Identificar percepciones de odontólogos (EC) sobre causas de exposición a material biológico, caracterizar cambios de comportamiento y prácticas de bioseguridad adoptadas por profesionales, luego de los accidentes. Métodos: Estudio cualitativo, transversal, retrospectivo, realizado en hospital público, São Paulo, Brasil. Se realizaron entrevistas, con dos cuestionarios semiabiertos y aplicados en dos grupos de $20 \mathrm{CD}$ cada uno, de 2008 a 2012, seleccionados, de la notificación de 103 accidentes, por la Comisión de Control de Infecciones Hospitalarias (CCIH). Aprobado por Comité de Ética en Investigación (CEP). Resultados: Momento del accidente y los cambios que se produjeron permitieron la categorización del estudio, respectivamente: Orden Personal, Orden Técnica, Orden de Trabajo, Recurrencia de Accidentes y Prevención de Accidentes. Ambos, la categoría Orden Personal reportó factores predisponentes para la ocurrencia de accidentes como falta de atención, distracción, estrés y fatiga. Los cambios ocurridos tras el accidente estuvieron relacionados: mayor autocuidado, atención y

\footnotetext{
${ }^{1}$ Secretaria de Estado da Saúde de São Paulo, São Paulo - SP.`E-mail: katiasantosdentista@gmail.com

2 Instituto de Infectologia Emílio Ribas, São Paulo - SP.
} 
bioseguridad. Conclusión: Cambios de comportamiento se relacionaron con prácticas de bioseguridad, adherencia a equipos de protección personal (EPP), mejora dental, autocuidado atención, límites personales y profesionales. Los cambios revelaron buenas prácticas de trabajo, adherencia vacunación completa y sugerencia de protocolos de atención, como apoyo a seguridad laboral.

Palabras clave: Contención de riesgos biológicos, Accidentes de trabajo, Prevención de accidentes.

\section{INTRODUÇÃO}

Os acidentes com material biológico representam um risco ocupacional aos profissionais da odontologia (NOGUEIRA AS, et al.,2016). Em tempos atuais, condutas de biossegurança são necessárias, nas práticas odontológicas (FARIA MHD, et al., 2020) para, evitar contaminação cruzada (TUÑAS ITC, et al., 2020), propagação de diversos vírus, como o coronavírus causador da COVID-19 e evitar disseminação de doenças infectantes, pelas secreções orais e nasais dos pacientes, a fim de proteger profissionais e auxiliares (YANG Y, et al., 2020).

Atualmente, para os profissionais da odontologia há um risco potencialmente elevado para a contaminação com coronavírus, principalmente o SARS-CoV-2, causador da COVID-19, devido à exposição constante de saliva, sangue, partículas aerossolizadas e a provável inalação deste material, por meio de trabalhos executados em indivíduos assintomáticos infectados e contato direto com a mucosa oral, instrumentos e superfícies contaminadas (IZZETTI R, et al., 2020).

O uso de instrumentos rotatórios e a inalação de partículas de sangue aerossolizadas durante os procedimentos odontológicos causam, nos cirurgiões-dentistas riscos e temores de contaminação pelo vírus da hepatite $B(\mathrm{HBV})$, vírus da hepatite $\mathrm{C}$ (HCV) e vírus da imunodeficiência humana (HIV) (HARIDI HK, 2016).

Dados da World Health Organization (WHO, 2015) relatam que a hepatite foi considerada como pandemia, por causar a morte de 1,4 milhões de pessoas (47\%) infectadas com o vírus, principalmente, o da hepatite B (HBV). Diretrizes e recomendações foram criadas, nos países africanos e asiáticos, a fim de alertar sobre os riscos da infecção, formas de prevenção e implantação de políticas públicas. Segundo o Centers for Diseases Control and Prevention (CDC, 2015) os profissionais da saúde são importantes para alertar sobre a vacinação contra o HBV, profilaxia pós-exposição com acidentes perfurocortantes ou outras exposições de ordem ocupacional.

O número real de acidentes com material biológico em profissionais da saúde não é conhecido (WHO, 2002). O CDC, nos EUA, estima que anualmente ocorram aproximadamente 385.000 acidentes com materiais perfurocortantes envolvendo trabalhadores da saúde em diversos centros (CDC, 2015). Os acidentes percutâneos com exposição a material biológico estão associados principalmente com a transmissão do HBV, do HCV e do HIV e outras doenças infecciosas (HSIN-CHUNG C, et al., 2012).

O risco estimado de contaminação por HIV, por meio de material contaminado, considerando-se mucosa íntegra, é em torno de 0,09\%, já a exposição de pele íntegra tem risco inferior (KUHAR DT et al., 2013). O acidente de trabalho com materiais perfurocortantes proporciona intenso estresse físico e psíquico, além de mudanças psicossociais, em decorrência da necessidade de acompanhamento sorológico e, consequentemente, da espera de um provável resultado indicativo de soroconversão, da ingestão de medicamentos antirretrovirais (quando indicados), da vacinação e do uso de imunoglobulinas, conforme a prescrição indicada (BENNADI D, et al., 2014)

No Brasil, os acidentes de trabalho com perfurocortantes e materiais biológicos se evidenciaram a partir de 1970 (BARBOZA DB, et al., 2004). Na década de 1980, com a epidemia da AIDS (síndrome da imunodeficiência adquirida), seguido de muitas publicações referentes ao tema e sobre a forma de como contrair a doença, muitos profissionais de saúde se atemorizaram com o risco de se contaminar e começaram a fazer uso de equipamentos de proteção individual (EPI) (BARBOZA DB, et al., 2004).

O objetivo deste estudo foi identificar a percepção dos cirurgiões-dentistas sobre as possíveis causas de exposição a material biológico, caracterizar mudanças comportamentais e as práticas de biossegurança adotadas pelos profissionais, após os acidentes para segurança, no trabalho odontológico. 


\section{MÉTODOS}

Foi realizado um estudo transversal qualitativo e retrospectivo, no período de 2008 a 2012, que utilizou dados obtidos da Ficha de Notificação de Acidentes com Material Biológico (FNAMB), desenvolvida e preenchida pela equipe da Comissão de Controle de Infecção Hospitalar $(\mathrm{CClH})$, de um hospital de referência para doenças infectocontagiosas, localizado na capital de São Paulo, Brasil.

Os profissionais, dentistas, selecionados neste estudo foram atendidos no pronto-socorro, seguindo normas do Ministério da Saúde (MS) e os retornos foram agendados, de acordo com a necessidade, no ambulatório de acidentes. O período de estudo não apresentou dados mais recentes, pois o ambulatório de atendimento dos acidentes, no referido hospital, sofreu modificações e o serviço foi descontinuado passando para os postos de saúde, próximo ao local de trabalho, onde as vítimas sofriam o acidente.

A ficha FNAMB era preenchida por um médico e a equipe avaliava a necessidade, ou não da continuidade da quimioprofilaxia, e estabelecia o seguimento ambulatorial de acordo com as variáveis epidemiológicas e os resultados das sorologias colhidas.

Um banco de dados foi organizado contendo as seguintes informações: identificação pessoal, dados profissionais, acidentes prévios, acidente atual, tipo de acidente, material biológico envolvido, instrumento, momento do acidente, causa do acidente, uso EPI, dados do paciente contaminante (chamado de PacienteFonte), antecedentes do profissional acidentado, conduta clínica e retornos com acompanhamento seguindo os intervalos de tempo de seis semanas, três meses, seis meses e um ano.

O critério de inclusão deste estudo referiu-se aos Cirurgiões-Dentistas (CD) formados, independentemente da sua especialidade ou tempo de formado e notificados no serviço de atendimento da CCIH do hospital de referência que sofreram acidentes com perfurocortantes e material biológico contaminado, no período de 2008 a 2012. A análise de discurso foi realizada, de acordo com a temática apresentada pelos entrevistados.

Neste período, foram notificados 103 casos de acidentes únicos em CD atendidos no pronto-socorro do referido hospital, dos quais 40 foram selecionados, por atenderem aos critérios de inclusão, para responder entrevista semiestruturada, com um questionário, pré-testado e dividido em duas partes: A) informações pessoais e profissionais e B) dados do acidente com perfurocortante.

Do total dos 40 selecionados, 20 foram entrevistados pessoalmente durante as consultas no ambulatório, pois se encontravam em tratamento no local da pesquisa, no período de 2011 a 2012. Os 20 restantes foram selecionados pelos prontuários arquivados na CCIH, no período de 2008 a 2010 que, após contato telefônico prévio, aceitaram o convite para responder ao questionário em local e hora escolhidos pelos participantes, que deram preferência ao local de trabalho, não havendo mais ninguém durante a entrevista. O tempo médio de duração da entrevista era de 20 minutos. Os discursos descritos sobre o acidente dos participantes foram enumerados, conforme as fichas catalogadas para elaboração do banco de dados.

Os acidentes foram divididos em duas fases chamados de $1^{\circ}$ momento e $2^{\circ}$ momento. $01^{\circ}$ momento refere-se aos acidentes ocorridos e dados de anamnese coletados. O $2^{\circ}$ momento trata-se de mudanças ocorridas depois do acidente.

Dentro dessas fases foram elaboradas categorias que descrevem os motivos dos acidentes, no $1^{\circ}$ momento, as quais foram nomeadas como: Ordem Pessoal: são os motivos de acidentes que acontecem por alterações psicológicas; Ordem Técnica: são os motivos de acidentes que acontecem por inadequação do uso da técnica odontológica; Ordem de Trabalho: são os motivos de acidentes que acontecem ligados à execução do trabalho e seus extenuantes; Reincidência de Acidente: são novos acidentes que acontecem em curto período de tempo em relação à notificação do primeiro.

No $2^{\circ}$ momento, as categorias se referem às mudanças de comportamento após os acidentes e foram nomeadas como: Ordem Pessoal: trata de mudanças psicológicas tomadas de forma consciente, para melhorar a qualidade de vida; Ordem Técnica: é a melhora da adesão aos métodos técnicos de trabalho; Ordem de Trabalho: novas percepções de como lidar com atividades laborais; Prevenção de Acidentes: são atitudes assimiladas com a intenção de diminuir riscos de novos acidentes. 
Este estudo foi aprovado pelo Comitê de Ética em Pesquisa (CEP), pela Plataforma Brasil (Número CAAE: 15709913.4.0000.0061) e todos os participantes da pesquisa assinaram o termo de consentimento livre e esclarecido (TCLE). A (Figura 1) descreve os passos metodológicos adotados.

Figura 1 - Fluxograma dos procedimentos metodológicos.

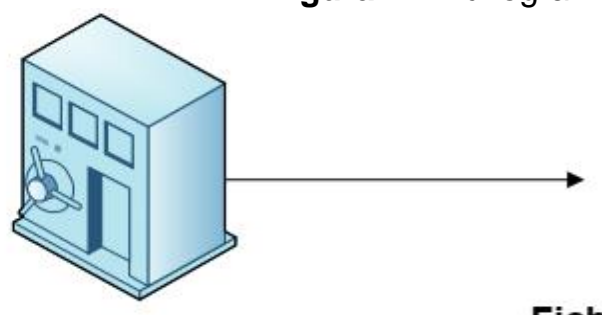

Fichas de Cirurgiões-

Dentistas

Com 103 acidentes notificados 2008-2012

(FNAMB)

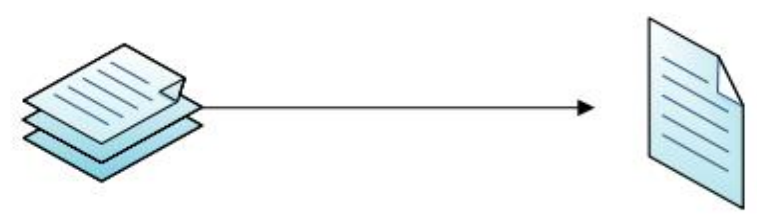

Seleção de Entrevistados

40 cirurgiões-dentistas Entre 2008-2012

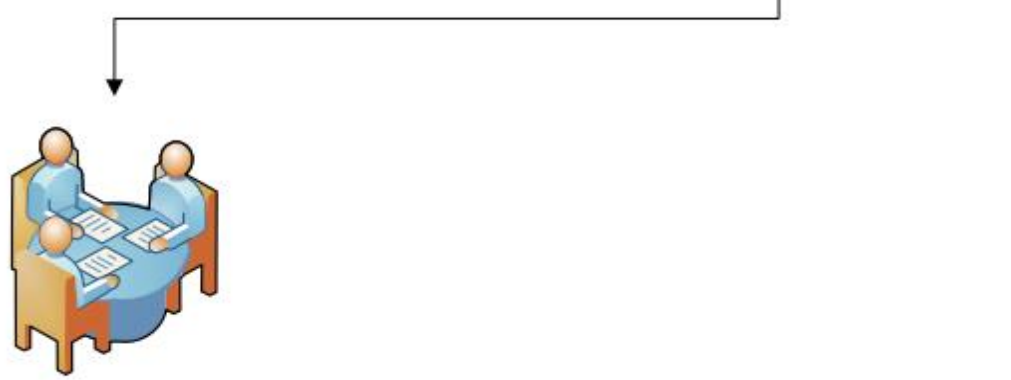

\section{Entrevista Semi-Estruturada com dois Questionários}

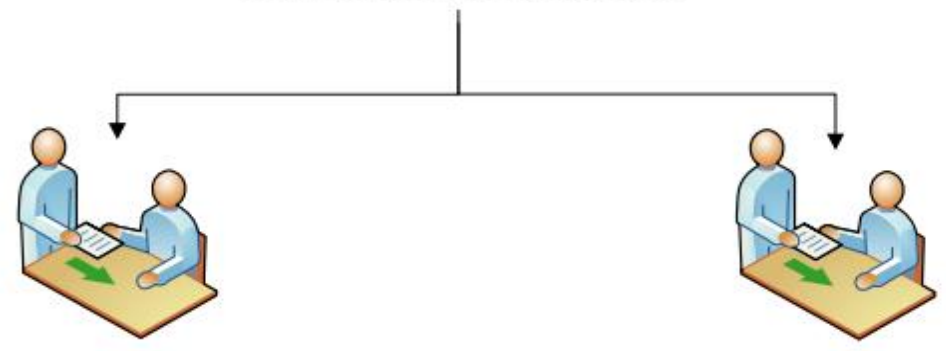

\section{Entrevistados após Seleção} de Prontuário (2008-2010)

(2008: $N=5 ;$ 2009: $N=5 ; 2010: N=10$ ) Total: $\mathrm{N}=20$

\section{Entrevistados durante Consulta} Ambulatorial (2011-2012)

(2011: $N=9 ; 2012: \mathrm{N}=11$ ) Total: $\mathrm{N}=20$

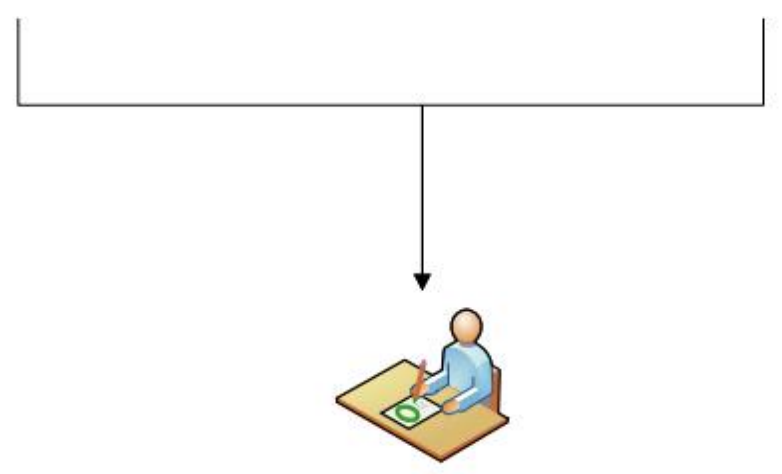

Análise Temática

Fonte: Santos KF e Cavalcante NJF, 2021. 


\section{RESULTADOS}

Quanto às informações sociodemográficas dos $40 \mathrm{CD}$ entrevistados, a média de idade dos profissionais foi de 36,5 em anos, o sexo predominante foi o feminino e a maioria dos profissionais entrevistados (62,5\%) era casada. A cor predominante dos profissionais era branca (85\%) e os outros $15 \%$ eram de cor amarela, nascidos no estado de São Paulo (67,5\%). Apenas uma profissional entrevistada era funcionária do hospital de estudo. Todos os entrevistados eram graduados em Odontologia, somente $15 \%$ não possuíam especialidade específica e a área mais destacada, de atuação, foi a Clínica Geral, com 77,5\% dos profissionais atuando em consultórios particulares. O tempo médio de trabalho na profissão foi de 14,7 anos e o turno de trabalho predominante $(92,5 \%)$ foi o diurno.

Todos os dentistas dessa amostra foram vacinados contra hepatite $B$, mas nem todas as doses foram administradas corretamente. No, (Quadro 1) estão descriminadas as quatro categorias referentes ao momento que ocorreu o acidente ( $1^{\circ}$ momento), de acordo com a análise temática.

Quadro 1. Descrição sumária da percepção dos cirurgiões-dentistas quanto aos motivos que levaram ao acidente, de acordo com os discursos.

\begin{tabular}{|c|c|c|c|c|}
\hline Categorias & Ordem Pessoal & Ordem Técnica & Ordem do Trabalho & $\begin{array}{c}\text { Reincidência de } \\
\text { Acidente }\end{array}$ \\
\hline \multirow{6}{*}{$\begin{array}{l}\text { Motivos } \\
\text { dos } \\
\text { acidentes }\end{array}$} & $\begin{array}{c}\text { Desatenção, } \\
\text { distração, euforia, } \\
\text { descuido }\end{array}$ & $\begin{array}{c}\text { Técnica } \\
\text { odontológica } \\
\text { inadequada }\end{array}$ & $\begin{array}{l}\text { Sobrecarga de } \\
\text { trabalho }\end{array}$ & $\begin{array}{c}\text { Três pessoas } \\
\text { notificaram como sendo } \\
\text { um segundo acidente }\end{array}$ \\
\hline & Estresse & Falta de $\mathrm{EPI}^{\star *}$ & $\begin{array}{l}\text { Insatisfação } \\
\text { profissional }\end{array}$ & \\
\hline & Fadiga & $\begin{array}{l}\text { Negligência do } \\
\text { manuseio do } \\
\text { material }\end{array}$ & & \\
\hline & $\begin{array}{l}\text { Psicologicamente } \\
\text { alterada }\end{array}$ & Imprudência & & \\
\hline & $\begin{array}{l}\text { Medo de doenças } \\
\text { transmissíveis } \\
(\mathrm{HIV} \text { e HCV })^{*}\end{array}$ & & & \\
\hline & $\begin{array}{c}\text { Falta de } \\
\text { autocuidado }\end{array}$ & & & \\
\hline
\end{tabular}

Nota: *HBV não fez parte deste item, pois os participantes eram vacinados. ${ }^{* \star}$ Não utilizavam durante a atividade profissional.

Fonte: Santos KF e Cavalcante NJF, 2021. Baseado em Santos KF, 2014.

Na categoria Ordem Pessoal, a falta de atenção profissional no trabalho e o estresse foram os discursos mais prevalentes.

$\mathrm{Na}$ Ordem Técnica houve destaque da negligência profissional. Muitas vezes, o CD conhecia as medidas de biossegurança e a indicação do uso de EPI, para lidar com o material odontológico contaminado, mas negligenciava os cuidados necessários. Foram relatadas inadequações de técnica odontológica como falta de lavagem das mãos, sutura guiada pelo dedo e reencape de agulhas anestésicas. Quando comparado o tempo de formação profissional, os que possuíam menor tempo relataram saber o que fazer e onde buscar atendimento adequado, em casos de acidentes com material biológico.

Muitas vezes, as razões que causam o acidente, como pressa, economia de EPI, banalização do acidente, não são consideradas como fatores de risco pelos dentistas. Na categoria Ordem de Trabalho, a sobrecarga do trabalho profissional foi relatada como a principal causa dos acidentes. E na categoria Reincidência de Acidentes, três profissionais notificaram como sendo o segundo acidente.

\section{Mudanças Ocorridas após o Acidente}

As mudanças de comportamento ocorridas após o acidente (2ำ momento) referem-se aos resultados obtidos por meio de uma pergunta aberta ( $O$ que mudou na rotina de trabalho e na sua vida depois do acidente?), que nortearam as quatro categorias elaboradas no (Quadro 2). 
Quadro 2 - Mudanças ocorridas no comportamento dos cirurgiões-dentistas após exposição a material biológico ( $2^{\circ}$ momento), de acordo com a ordem de importância dos relatos profissionais.

\begin{tabular}{|c|c|c|c|c|}
\hline Categorias & Ordem Pessoal & Ordem Técnica & Ordem do Trabalho & $\begin{array}{c}\text { Prevenção de } \\
\text { Acidentes }\end{array}$ \\
\hline \multirow{10}{*}{$\begin{array}{l}\text { Mudanças de } \\
\text { Comportamento } \\
\text { após o Acidente }\end{array}$} & $\begin{array}{c}\text { Aumento no } \\
\text { autocuidado, com } \\
\text { criteriosidade } \\
\end{array}$ & $\begin{array}{c}\text { Mudança da técnica } \\
\text { odontológica }\end{array}$ & $\begin{array}{c}\text { Delegar atividades } \\
\text { à equipe de } \\
\text { trabalho }\end{array}$ & $\begin{array}{l}\text { Noções de } \\
\text { alteridade }\end{array}$ \\
\hline & $\begin{array}{l}\text { Redução do } \\
\text { excesso de } \\
\text { autoconfiança }\end{array}$ & $\begin{array}{c}\text { Melhora na } \\
\text { orientação para } \\
\text { conduzir casos } \\
\text { clínicos }\end{array}$ & Troca de emprego & Heterocuidado \\
\hline & $\begin{array}{c}\text { Melhora na } \\
\text { autopercepção }\end{array}$ & $\begin{array}{l}\text { Atenção na limpeza } \\
\text { dos instrumentais }\end{array}$ & $\begin{array}{l}\text { Melhora na } \\
\text { percepção do } \\
\text { trabalho }\end{array}$ & $\begin{array}{l}\text { Seriedade na } \\
\text { prevenção dos } \\
\text { acidentes }\end{array}$ \\
\hline & $\begin{array}{l}\text { Adesão à terapia } \\
\text { antirretroviral } \\
\text { (TARV) }\end{array}$ & $\begin{array}{l}\text { Uso adequado de } \\
\text { EPI }\end{array}$ & & \\
\hline & $\begin{array}{l}\text { Melhora na } \\
\text { atenção }\end{array}$ & & & \\
\hline & $\begin{array}{l}\text { Reconhece } \\
\text { limites }\end{array}$ & & & \\
\hline & $\begin{array}{c}\text { Mudança de } \\
\text { emprego }\end{array}$ & & & \\
\hline & $\begin{array}{c}\text { Melhora na } \\
\text { condição pessoal }\end{array}$ & & & \\
\hline & $\begin{array}{l}\text { Troca de área ou } \\
\text { especialidade }\end{array}$ & & & \\
\hline & $\begin{array}{c}\text { Diminuição de } \\
\text { carga de trabalho }\end{array}$ & & & \\
\hline
\end{tabular}

Fonte: Santos KF e Cavalcante NJF, 2021. Baseado em Santos KF, 2014.

$\mathrm{Na}$ Ordem Pessoal ficaram agrupados os discursos que revelaram aspectos dos entrevistados quanto à percepção de suas mudanças no seu cotidiano e após o acidente de trabalho de acordo com os motivos no (Quadro 2). A Ordem Técnica mostrou o cirurgião-dentista como um profissional vulnerável a riscos ocupacionais, devido às características peculiares à sua atuação profissional. Com a melhora do domínio técnico-odontológico, nos procedimentos executados, há uma maior segurança para se evitar acidentes com perfurocortantes.

Destaca-se na categoria Ordem de Trabalho, o estresse causado pela sobrecarga profissional que pode, eventualmente, evoluir para síndrome de Burnout com grande desgaste físico e emocional. Para melhorar a produtividade profissional é necessário delegar tarefas e contratar auxiliar odontológico que possa ajudar no rendimento profissional, a fim de diminuir os acidentes com material biológico (QUELUZ DP, 2005).

$\mathrm{Na}$ categoria Prevenção de Acidentes apareceram relatos que reportavam as noções de empatia, heterocuidado e seriedade na forma de agir quanto à prevenção de acidentes. De acordo com as categorias elaboradas a partir dos relatos mais relevantes destacam-se:

O Aumento no Autocuidado e Criteriosidade, na ordem pessoal, sugerem uma possibilidade para autoobservação profissional, melhora da percepção do corpo físico, mental e emocional que visa à melhoria da qualidade de vida. Ao se perceber, o profissional se torna mais criterioso, menos negligente consigo mesmo e capaz de cometer menos acidentes. $O$ discurso a seguir expõe tais aspectos:

"Tento tomar mais cuidado durante as cirurgias quando não estou muito sobrecarregada porque nestes casos eu entro em desespero e não há um planejamento na minha agenda que é controlada por outras pessoas [...] Eu tomo mais cuidado comigo, pois também viajo pela [rodovia] Dutra para trabalhar e eu aprendi a dar muito valor para a vida humana e também gostaria de ter mais voz ativa para cuidar de todos no serviço". (Profissional 71). 
A Mudança da Técnica está associada à execução de procedimentos odontológicos geradores de ansiedade profissional e que podem desencadear acidentes, independentemente da colaboração do paciente. Quando o profissional consegue observar o seu próprio comportamento e fica atento, não somente, aos aspectos técnicos da prática odontológica, mas também aos efeitos desta prática sobre o repertório de comportamentos do paciente e dos acompanhantes, se estabelece uma interação de segurança e tranquilidade, o que facilita a realização dos procedimentos dentários, de forma rápida e segura, para todos os envolvidos, com a diminuição dos riscos de acidentes (POSSOBON RF, et al., 2007). Por exemplo, em:

"Já tinha medo de acidentes! E agora eu tomo muito mais cuidado, mudei a técnica cirúrgica para me sentir mais segura." (Profissional 69).

A noção de Alteridade reflete a humanização e os cuidados em saúde com o próximo, respeitando a autonomia, liberdade, individualidade de cada um (ALMEIDA DV, 2012). Confirma-se na declaração a seguir:

"Em um momento que não se usava luvas, eu operei um paciente, que eu nem me lembro de quem era, e acabei contraindo hepatite $C$ e descobri muito tempo depois. Recentemente, eu atendi um paciente com AIDS, sofri um novo acidente com agulha e decidi terminar meu tratamento do vírus HIV, com acompanhamento, para não ter nenhuma surpresa e não queria mais nenhum problema para minha vida." (Profissional 106).

\section{DISCUSSÃO}

Shaghaghian S, et al. (2014) e Sharma A e Sharma S (2016) recomendaram que os profissionais da saúde expostos aos riscos de transmissão de HIV, HBV e HCV sejam adequadamente orientados quanto à transmissão de AIDS e hepatites, levando em conta: sangue visível, manuseio de materiais contaminados e aspectos emocionais seguidos de eventos de acidentes com perfurocortantes.

No estudo de Santos KF (2014), observou-se que a vacinação contra hepatite B estava incompleta, o uso de EPI foi negligenciado como medida protetiva para riscos de acidentes e 0 item de biossegurança mais utilizado foram às luvas.

A imunização dos profissionais de odontologia tem contribuído muito para reduzir os riscos de doenças infecciosas ocupacionais, como a hepatite B. No entanto, uma situação pode fazer parte no cenário da prática odontológica geral, como no caso dos autoacidentes, que ocorrem por conta do recapeamento de agulhas (LOKESH U, et al., 2014).

Dentro da prática odontológica, os $\mathrm{CD}$ têm a responsabilidade de fornecer conhecimento técnico-científico e atitude emocional para o tratamento de pacientes infectados pelo HIV, sobretudo porque lesões orais são comuns entre esses pacientes. Notadamente, ter conhecimento adequado sobre HIV/AIDS aumenta a confiança na capacidade de gerenciar pacientes infectados (OBEROI SS, et al., 2015).

Machado-Carvalhais HP, et al. (2008) conduziram uma pesquisa com estudantes de graduação em odontologia e acidentes com material biológico. Os autores mostraram que, dos 167 estudantes entrevistados, mais da metade relataram acidentes prévios, que foram classificados como: cutâneo, percutâneo e acidentes com mucosa. Os resultados do estudo corresponderam a uma taxa de 1,78\% episódios ocupacionais de exposição por aluno afetado o que corrobora com uma estimativa de acidentes que não é bem conhecida e está associado com várias doenças infecciosas (CDC, 2015).

Vale ressaltar que os acidentes com objetos pontiagudos podem influenciar negativamente o estilo de vida do trabalhador lesionado, devido ao estresse psicológico e outras mudanças, tais como: familiares, trabalhistas, práticas sexuais, suspensão da amamentação, além de outras, especialmente, antes dos resultados dos testes ficarem prontos e a possibilidade de soroconversão (SANTOS KF, 2014).

As cargas psíquicas no trabalho são justificadas por exposição permanente da atenção do profissional e intensa supervisão voltada aos cuidados do paciente, seguida de pressão psíquica, falta de conscientização do risco de acidente, monotonia e falta de criatividade (MORENO F e RUIZ CN, 2010). Dentre os sintomas psicológicos registrados pelos profissionais, há a diminuição da capacidade de concentração e aumento de 
ansiedade, nervosismo, depressão, raiva e medo. Tais estressores podem evoluir para a síndrome de burnout, que é um fenômeno psicológico conhecido como exaustão emocional, despersonalização e baixa realização profissional observados na prestação de serviços (MORENO F e RUIZ CN, 2010; JIN MU, et al., 2015).

No motivo dos acidentes ( $1^{\circ}$ momento), onde as categorias (ordem pessoal, ordem técnica, ordem de trabalho e reincidência de acidentes) são relatadas temos, na categoria Ordem Pessoal, a desatenção profissional no trabalho é a causa que mais se destaca para o acontecimento do acidente. Na Ordem Técnica, a negligência do profissional aparece, principalmente, relacionada à biossegurança, ou seja, o profissional conhece as medidas de proteção para manusear o material, mas não as utiliza de forma adequada, pois acredita que os acidentes não ocorrerão. Na categoria Ordem de Trabalho, a carga excessiva de trabalho do dentista surge como um contribuinte ao estresse no trabalho e favorece o acidente (SANTOS, KF, 2014).

De acordo com Kapoor V, et al. (2013), em revisão sistemática das lesões causadas por agulhas nos profissionais de odontologia, há uma vantagem no conhecimento dos dados sorológicos do paciente-fonte, pois essa informação permite a pronta adesão à profilaxia correta para cada caso. O conhecimento da sorologia do paciente-fonte permite a redução da TARV para o trabalhador lesado (KAPOOR V, et al., 2013). No estudo de Gupta N e Tak J (2011), quando a fonte não tinha sorologia para HIV, mas estava disponível para fazer um teste rápido, houve redução significativa nas indicações de TARV, pois, muitas vezes, o exame comum poderia levar mais de 48 horas para apresentar os resultados, criando ansiedade e expectativa ao profissional.

Quando os resultados sorológicos para HIV são desconhecidos, a profilaxia com terapia antirretroviral pode reduzir a possibilidade de uma infecção pelo HIV. No entanto, muitos profissionais interrompem o tratamento devido à intolerância à droga, que geralmente causa pânico em função dos efeitos colaterais, fazendo com que a medicação seja interrompida (SANTOS KF, 2014).

Wasti SP, et al. (2012) mostraram que os pacientes frequentemente interrompem os medicamentos antirretrovirais devido aos vários efeitos colaterais. Além disso, eles acreditam que o uso da medicação pode aumentar a chance de infecção pelo HIV. Finalmente, os resultados mostram que muitos profissionais têm medo de adquirir a aids, especialmente pelo estigma da doença.

Um dos aspectos relevantes nos protocolos pós-exposição inclui a notificação de acidentes ao Serviço de Medicina do Trabalho (WASTI SP et al., 2012). Embora a Norma Regulamentar-32 (NR-32) estabeleça a obrigatoriedade de relatar acidentes com objetos perfurocortantes, os profissionais geralmente não relatam (TIBÃES HBB, et al., 2014).

Os profissionais que trabalham em instituições privadas ou públicas são obrigados a notificar a medicina do trabalho; mas para os profissionais que trabalham na prática privada não há lugar específico de notificação e isso favorece a baixa adesão dos CD aos protocolos de pós-exposição ocupacional, influenciada pela falta de conhecimento, renda mensal dos profissionais autônomos, pausas regulares para ir aos locais de atendimento, faixa etária e classe socioeconômica dos entrevistados que sofreram acidente (MARTINS AMEBL, et al., 2010).

No presente estudo, identificamos que alguns acidentes ocorreram devido ao uso impróprio de técnicas odontológicas, como reencape de agulhas anestésicas.

Lee JJ, et al. (2014), em seu estudo com ferimentos cortantes ocasionados por agulha nos trabalhadores do departamento de odontologia, do Hospital Universitário Nacional de Taiwan, analisou fatores de risco associados com ferimentos e verificou-se que as agulhas e instrumentos perfurocortantes são muito usados nos procedimentos dentários e os trabalhadores da profissão odontológica são especialmente, propensos a estes ferimentos.

O comportamento seguro consiste em eliminar objetos cortantes e agulhas em um coletor apropriado com um dispositivo que permita separar a agulha e descartá-la sem a ajuda da outra mão para reduzir o risco de contaminação (LEE JJ, et al., 2014). 
No estudo de Goniewicz M, et al. (2012) mostrou que as lesões ocupacionais com objetos perfurocortantes ocorreram em tempos de estresse, seguidos por falhas técnicas odontológicas e falta de conhecimento profissional sobre como proceder antes do acidente.

Para os profissionais da odontologia e demais prestadores de serviço de saúde o uso de EPI atua como barreira protetiva e inclui: óculos de proteção, máscaras, luvas, bonés, protetores faciais, além de roupas apropriadas que são sempre indicadas em ambientes clínicos e hospitalares, em diferentes momentos, com doenças infectocontagiosas, mesmo durante o período da Pandemia da COVID-19 (SANTOS KF e BARBOSA M, 2020).

Os acidentes de trabalho com sangue podem ser mais bem gerenciados quando envolvem boas práticas de trabalho, organização profissional, instalações físicas adequadas, melhor capacitação técnica profissional, uso adequado de EPI, como instrumentos de biossegurança, fazer imunização completa contra doenças infecciosas, a fim de facilitar manuseio de instrumentos odontológicos contaminados e seguir protocolos que viabilizem a prevenção dos acidentes (SANTOS KF, 2014).

\section{CONCLUSÂO}

Os profissionais relataram mudanças de comportamento em relação à biossegurança, adesão ao uso de $\mathrm{EPI}$, aperfeiçoamento das técnicas odontológicas, maior autocuidado na atenção, nos limites pessoais e profissionais. As mudanças ocorridas revelaram boas práticas de trabalho, reorganização profissional, adesão à imunização vacinal completa e sugere-se que protocolos de atendimento, em casos de acidentes ocupacionais possam ser coadjuvantes na segurança do trabalho nos tempos atuais.

\section{REFERÊNCIAS}

1. ALMEIDA DV. Alteridade: ponto de partida da humanização dos cuidados em saúde? Rev Baiana Enf, 2012; 26(1): 399-407.

2. BARBOZA DB, et al. Acidentes de trabalho com pérfuro-cortante envolvendo a equipe de enfermagem de um hospital de ensino. Arq Ciênc Saúde, 2004; 11(2): 93-99.

3. BENNADI D, et al. Occupational hazards in dentistry. Res J Pharm Biol Chem Sci, 2014; 5(3): 1605-1614.

4. CENTERS FOR DISEASE CONTROL AND PREVENTION. About the Workbook for Designing, Implementing, and Evaluating a Sharps Injury Prevention Program [Internet]. Atlanta: CDC; Last updated Feb 11, 2015 [cited 2016 Oct 4]. Available from: https://www.cdc.gov/sharpssafety/resources.html

5. FARIA MHD, et al. Biossegurança em odontologia e COVID-19: uma revisão integrativa. Cad ESP Ceará, 2020; 14(1): 53-60.

6. GONIEWICZ M, et al. Injuries caused by sharp instruments among healthcare workers: international and Polish perspectives. Ann Agric Environ Med, 2012; 19(3): 523-527.

7. GUPTA N, TAK J. Needlestick injuries in dentistry. Kathmandu Univ Med J, 2011; 35(3): 208-212.

8. HARIDI HK, et al. Knowledge of dental health care workers' about standard precautions guidelines at health care facilities in hail region, Saudi Arabia. Int J Adv Res, 2016; 4(1): 1375-1385.

9. HSIN-CHUNG C, et al. Factors affecting occupational exposure to needlestick and sharps injuries among dentists in Taiwan: a nationwide survey. Plos One [Internet], 2012; 7(4): 1-6.

10. IZZETTI R, et al. COVID-19 Transmission in Dental Practice: Brief Review of Preventive Measures in Italy [Internet]. J Dent Res, 2020; 99(9): 1030-1038.

11. JIN MU, et al. Burnout and its related factors in Korean dentists. Int Dent J, 2015; 65(1): 22-31.

12. KAPOOR V, et al. Knowledge, awareness and practice regarding needle stick injuries in dental profession in India: a systematic review. Niger Med J, 2013; 54(6): 365-370.

13. KUHAR DT, et al. Updated US Public Health Service guidelines for the management of occupational exposures to human immunodeficiency virus and recommendations for postexposure prophylaxis. Infect Control Hosp Epidemiol, 2013; 34(9): 875-892.

14. LEE JJ, et al. Needlestick and sharps injuries among dental healthcare workers at a university hospital. J Formos Med Assoc, 2014; 113(4): 227-233.

15. LOKESH U, et al. Post exposure prophylaxis to occupational injuries for general dentist. J Indian Prosthodont Soc, 2014; 14(Suppl 1): 1-3.

16. MACHADO-CARVALHAIS HP, et al. Occupational exposure to potentially infectious biological material in a dental teaching environment. J Dental Educ, 2008; 72(10): 1201-1208.

17. MARTINS AMEBL, et al. Compliance with occupational post-exposure protocol for injuries among dental surgeons. Rev Saúde Pública, 2010; 44(3): 528-540.

18. MORENO F, RUIZ CN. Risk of suicide amongst dentists: Myth or reality? Int Dental J, 2010 Dec; 60(6): 411-418. 
19. NOGUEIRA AS, et al. Prevalência e notificações de acidentes de trabalho com exposição a material biológico na odontologia. Rev Ciênc Plural, 2016; 2(1): 102-119.

20. OBEROI SS, et al. Self-reported knowledge and attitude toward the treatment of HIV/AIDS infected individuals by the Dental Practitioners working in a public sector institute: a cross sectional study. J Educ Ethics Dent, 2015; 5(1): 14-19.

21. POSSOBON RF, et al. O tratamento odontológico como gerador de ansiedade. Psicol Estud, set/dez 2007; 12(3): 609616.

22. QUELUZ DP. Perfil dos profissionais auxiliares da odontologia e suas implicações no mercado de trabalho. Rev Odonto Ciênc,2005; 20(49): 270-280.

23. SANTOS KF, BARBOSA M. COVID-19 e a Odontologia na prática atual. Revista Eletrônica Acervo Saúde (REAS), 2020; 12(11): e5113.

24. SANTOS KF. Análise dos aspectos epidemiológicos dos acidentes ocupacionais, práticas de biossegurança e impacto na rotina de trabalho de cirurgiões-dentistas, após exposição a material biológico [tese]. São Paulo: Coordenadoria de Controle de Doenças, Secretaria de Estado da Saúde; 2014.

25. SHAGHAGHIAN S, et al. Knowledge, attitude and practice of dentists towards prophylaxis after exposure to blood and body fluids. Int J Occup Environ Med, 2014; 5(3): 146-154.

26. SHARMA A, SHARMA S. Assessment of knowledge and attitude among dental care workers towards patients affected with HIV/AIDS in a private dental college in India. Br J Med Med Res, 2016; 11(11): 1-7.

27. TIBÃES HBB, et al. Accidents at Work from Exposure to Biological Material Contamination of Viral Hepatitis "B" and "C" in a Brazilian Capital. Occup Dis Environ Med [Internet]. 2014; 2: 39-47.

28. TUÑAS ITC, et al. Doença pelo Coronavírus 2019 (COVID-19): uma abordagem preventiva para Odontologia. Rev Bras Odontol, 2020; 77:1-6.

29. WASTI SP, et al. Factors influencing adherence to antiretroviral treatment in Nepal: a mixed-methods study. PLoS One [Internet]. 2012; 7(5): e35547.

30. WORLD HEALTH ORGANIZATION (WHO). Guidelines for the prevention, care and treatment of persons with chronic hepatitis b infection. Geneva: WHO; 2015.

31. WORLD HEALTH ORGANIZATION (WHO). The World Health report, 2002: reducing risks, promoting healthy life [Internet]. 2002. Available from: http://www.who.int/whr/2002/en/whr02_en.pdf.

32. YANG Y, et al. Experience of Diagnosing and Managing Patients in Oral Maxillofacial Surgery during the Prevention and Control Period of the New Coronavirus Pneumonia. Chin J Dent Res, 2020; 23(1): 57-62. 